Article

\title{
Study on Unsteady Flow Based on Optimized Water Distribution Model in Irrigation District
}

\author{
Jingjing $\mathrm{Wu}^{1}{ }^{1}$ Jian Chen ${ }^{2}$, Yu Han ${ }^{1, *}$ and Tongshu $\mathrm{Li}^{1}$ \\ 1 College of Water Resources \& Civil Engineering, China Agricultural University, Beijing 100083, China; \\ S20193091621@cau.edu.cn (J.W.); s20193091620@cau.edu.cn (T.L.) \\ 2 College of Engineering, China Agricultural University, Beijing 100083, China; jchen@cau.edu.cn \\ * Correspondence: yhan@cau.edu.cn; Tel.: +86-182-0161-0386
}

Received: 31 December 2019; Accepted: 14 February 2020; Published: 20 February 2020

\begin{abstract}
The canal delivery system is the main infrastructure of agricultural irrigation. The efficiency of water use in agriculture can be achieved by mastering the dynamic process of unsteady flow in the channel. In this study, an unsteady flow model for the calculation of the water flow transition information of the river channel during the water distribution process was established, based on the water distribution scheme given by the backtracking-search algorithm (BSA). This model was more suitable for areas with inefficient channel systems. The research areas included the main irrigation channels in Xiying City, which is one of the typical agricultural areas in northwestern China. The scheme obtained by optimal solution proposed for Xiying Irrigation District was feasible. According to the results of the flow simulations, the sluice gate calculation correlation could determine the change process of the gate opening of each channel, which provided a basis to realize the modernization of the irrigation area.
\end{abstract}

Keywords: irrigation canal system; canal water distribution scheme; backtracking-search algorithm; feasibility analysis; sluice gate

\section{Introduction}

Economic and population growth, changes in eating habits and rural and urban drifts put pressure on water resources [1]. In addition, water, energy and food are inextricably inter-linked and are vital for the subsistence and development of human beings [2,3]. Therefore, it is important for researchers to find a way to promote sustainable water use and meet the needs of the growing population. Changes in the availability of water resources strongly affect food production, especially in developing countries, which have experienced several resource shortages [4]. However, due to various factors, such as irrigation methods and technologies, water equipment and the uneven distribution of water resources in China, it is difficult to further the improvement of agricultural water use efficiency; therefore, the maximization of the irrigation water value is of great significance for agricultural development in arid areas [5]. For example, the goal of sustainable utilization can be achieved by using the economic value of water as a starting point for the optimal allocation of water for crop irrigation and exploring a reasonable agricultural water plan [5]. It can also provide a basis for the improvement of the utilization efficiency of irrigation water and can contribute to addressing water scarcity and food security issues $[6,7]$.

The rise of intelligent algorithms in recent years has provided new ideas to solve the complex models of irrigation water resources. In the last century, Hall and Nathan [8] proposed a dynamic programming model to solve the water allocation of supply, considering dollar benefits, cost, etc. They were followed by other researchers who proposed different intelligent algorithms to solve the optimal configuration problems [9-15]. However, an intelligent algorithm for the optimal solution of 
global water distribution is often difficult to achieve due to the complexity and variability of certain factors such as objective function and constraint conditions. Jin et al. [16] and Leela Krishna et al. [17] proposed the Genetic Algorithm and Non-Linear Programming (GA-NLP) hybrid algorithm and the dynamic double-interval programming model and achieved the global optimal solution. The traditional intelligent algorithm for multi-objective optimization of water distribution in the channel system was not optimal; therefore, Sun et al. [18] did not rely on the objective function and optimized a small number of parameters to solve the optimal type of method. In the process of "constant flow, control open", Civicioglu [19] proposed the backtracking-search algorithm for the optimization model of water distribution in an irrigation area and provided a solution for the water distribution scheme, which had the shortest water distribution time and the most stable water flow delivery. It was different from other algorithms because of its simple structure and single control parameter. Its performance was not sensitive to the initial value of the control parameter. Moreover, it was efficient, fast and capable of solving multi-model problems and was suitable for different types of optimization problems [20,21].

Reasonable planning of water distribution schedules for canal systems can reduce losses caused by water seepage and improve the utilization efficiency of irrigation water. Although many algorithms can optimize water distribution schemes, few studies have verified the feasibility of these optimization results in flow dynamics. Qi et al. [22] proposed that to optimize the configuration of water resources, real-time risk dispatching, intelligent management technology and coupling technology can be strengthened. When the water distribution scheme was initiated, the water level and flow rate of the canal changed along with time and process due to unsteady flow, which reflected the channel flow [23]. To calculate the optimization of water allocation in irrigation districts, only the utilization efficiency of water resources was considered; the real-time transition process of water flow during the actual operation in the current situation was not considered. However, field experiments are usually site-specific, expensive and time consuming, and the water distribution scheme of an irrigation district is not easily measured until reliability is assured. Therefore, establishing the numerical simulation of channel hydrodynamics based on the optimized water distribution model will be an effective and feasible method.

The basic theory for channel hydrodynamic simulation is the de Saint-Venant system of equations, which was proposed by Laplace and Lagrange [24]. It provided new ideas for the subsequent studies of unsteady flow problems in open channels. The in-depth studies of many researchers at home and abroad have proposed and improved various solutions for solving equations, laying a solid foundation to develop the numerical simulation of open channel hydrodynamics. With continuous development in the theory and the gradual popularization of modern computer technologies, the numerical simulation of unsteady flow has been fully developed and various calculation models have been proposed. There are many kinds of solving algorithms for open channel hydrodynamic simulation. Various algorithms have been gradually matured after years of applications and improvements. However, the verification of solution feasibility by coupling the optimal water distribution process with the hydrodynamic simulation is a common practice. Considering the uniqueness of the backtracking-search algorithm (BSA), in this study some channels of the Xiying Irrigation District in the Shiyang River basin were taken as the research objects, and the results of the BSA were coupled with the hydrodynamic simulation in order to optimize and analyze the regional irrigation regime. On the basis of Sun et al. [18], the problem of implementation was considered after the optimization of the solution. The operations of the hydrodynamic calculation model and the output of the results were used to analyze the feasibility of the scheme given by the BSA. On the basis of the new irrigation feasible scheme and the hydrodynamic information, the variation in the opening degree of each gate was calculated to provide a reference for a water-saving and efficient irrigation system in Xiying. 


\section{Materials and Methods}

\subsection{Description of the Study Area}

As one of the eight major tributaries in the upper region of the Shiyang River basin, the runoff production area of the Xiying River is located in the Qilian Mountains above the mountain outlet. The main source of runoff is atmospheric precipitation, while the melting of ice and snow acts as another small supply. This area has a large temperature difference between day and night and has low rainfall. According to the observation data of Wuwei Meteorological Station, the annual average temperature of this area is $7.7^{\circ} \mathrm{C}$, while the average annual evaporation and rainfall is $2021 \mathrm{~mm}$ and $158.4 \mathrm{~mm}$, respectively. This area is a part of the Shiyang River irrigation area in northwestern China, which is water scarce and irrigated by a canal system. It relies on the water channels from rivers to fields in the irrigated area to meet the needs of agricultural water.

In this study, the main canal of the irrigation area along with five secondary canals of the lower level were selected as research objects for the simulation calculation and design optimization. Figure 1 shows the distribution diagram of the canal system in the irrigation area and describes the approximate location and connections of the irrigation system in the calculated area. The data for the relevant parameters including the basic data of each channel, such as channel length, and size, are listed in Table 1. The data related to the main canal and branch canals of the Xiying main canal were collected from the special plan of the water-saving transformation project for the Xiying irrigation area in 2008, the statistical yearbook of water conservancy in Gansu Province, the general survey and registration form of the water conservancy project in the Xiying irrigation area and the detailed list of channel projects in the Xiying irrigation area.

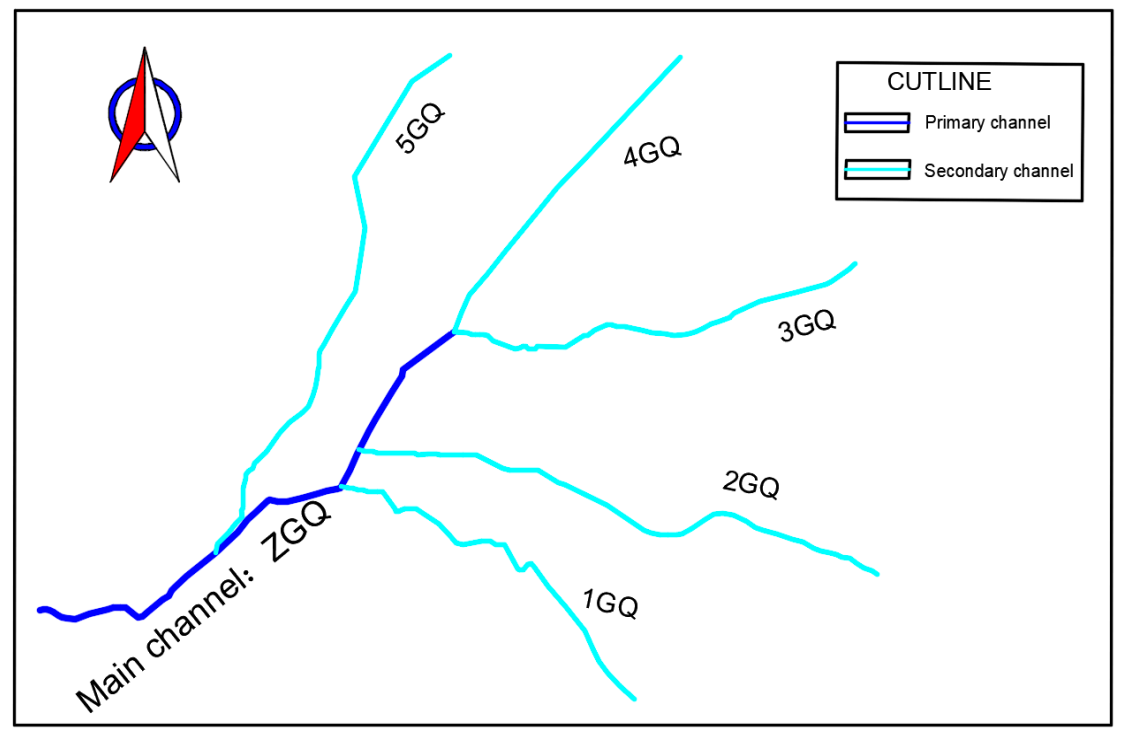

Figure 1. Distribution sketch of canal system for Xiying Irrigation District.

Table 1. Channel data.

\begin{tabular}{ccccc}
\hline Name & Length $(\mathbf{m})$ & Section Type & Size $(\mathbf{m})$ & Longitudinal Slope \\
\hline ZGQ & 10,920 & Trapezoid & $\mathrm{b}=9.0, \mathrm{~h}=3,1=1: 0.75$ & $1 / 200$ \\
1GQ & 15,894 & Trapezoid & $\mathrm{b}=1.6, \mathrm{~h}=3,1=1: 0.25$ & $1 / 80$ \\
2GQ & 22,110 & Trapezoid & $\mathrm{b}=1.6, \mathrm{~h}=2.5,1=1: 1.5$ & $1 / 80$ \\
3GQ & 15,350 & Trapezoid & $\mathrm{b}=1.2, \mathrm{~h}=1.5,1=1: 1.2$ & $1 / 80$ \\
4GQ & 15,830 & Trapezoid & $\mathrm{b}=1.5, \mathrm{~h}=1.2,1=1: 1.5$ & $1 / 80$ \\
5GQ & 14,000 & Trapezoid & $\mathrm{b}=1.2, \mathrm{~h}=1.8,1=1: 1.5$ & $1 / 80$ \\
\hline
\end{tabular}


The two-stage channel system in the Xiying Irrigation District, which was selected for the study, consisted of one primary canal and five secondary canals. The irrigation period was 30 days, and the estimated water supply was 5.535 million $\mathrm{m}^{3}$. The channel design parameters and the coefficients required for the optimization model are listed in Tables 2 and 3, respectively.

Table 2. Channel system design parameter.

\begin{tabular}{cccc}
\hline Number & Name & Design Flow Rate $\left.\mathbf{( m}^{\mathbf{3}} / \mathbf{s}\right)$ & Irrigation Quota $\left(\right.$ Million $\left.\mathbf{~}^{\mathbf{3}}\right)$ \\
\hline 2019 & ZGQ & 8.41 & 0.256 \\
1 & 1GQ & 1.48 & 0.323 \\
2 & 2GQ & 2.73 & 0.711 \\
3 & 3GQ & 2.08 & 0.932 \\
4 & 4GQ & 1.93 & 0.499 \\
5 & 5GQ & 2.67 & 0.436 \\
\hline
\end{tabular}

Table 3. Channel distribution model coefficient [18].

\begin{tabular}{cc}
\hline Parameters & Value \\
\hline Sub-channel minimum flow coefficient $\alpha_{\mathrm{dj}}$ & 0.6 \\
Sub-channel auxetic flow coefficient $\alpha_{\mathrm{uj}}$ & 1.2 \\
Sup-channel minimum flow coefficient $\mathrm{J}_{\mathrm{d}}$ & 0.4 \\
Sup-channel auxetic flow coefficient $\mathrm{J}_{\mathrm{d}}$ & 1.2 \\
The reduction coefficient of anti-seepage measures $\beta_{\mathrm{j}}$ & 0.5 \\
Canal bed soil permeability coefficient $\mathrm{A}_{\mathrm{j}}$ & 3.4 \\
Drainage bed soil permeability index $\mathrm{m}_{\mathrm{j}}$ & 0.5 \\
\hline
\end{tabular}

\subsection{Backtracking-Search Algorithm (BSA)}

Sun et al. [18] proposed a method to obtain the computational functions required for BSA simulations. The objective function is given as follows:

$$
\min _{j}^{\prime}=Q-\left(\sum_{m=1}^{j} G_{m}-\sum_{n=1}^{j-1} G_{x_{n}}\right)
$$

where $j$ indicates the number of times for backtracking, $Q_{j}^{\prime}$ is the remaining flow after backtracking $j$ times, $Q$ is the design flow of the main canal in the irrigation area, $\sum_{m=1}^{j} G_{m}$ is equal to the sum of the design flow rates of the branch canals selected by backtracking $j$ times previously and $\sum_{n=1}^{j-1} G_{x_{n}}$ the sum of the flow design of the branch canals prior to the completion of irrigation tasks in the previous $j-1$ backtracking selections, while the number of branch canals varies from 1 to $n$.

The remaining constraints are as follows:

(1) Time constraints

$$
\begin{gathered}
0 \leq t_{n}^{0} \leq t_{n}^{1} \leq T \\
t_{x_{j}}>0, x_{j} \in I_{1}\left[i_{1}\right] \text { or } x_{j} \in I_{2}\left[i_{2}\right] \ldots x_{j} \in I_{j}\left[i_{j}\right] \\
t_{x_{j}}=\min \left(t_{I_{1}}-\sum_{n=1}^{j-1} t_{x_{n}}, t_{I_{2}}-\sum_{n=2}^{j-2} t_{x_{n}} \ldots t_{I_{j}}\right)
\end{gathered}
$$

where $t_{n}^{0}$ is the irrigation start time for the branch canal " $n$ " and $t_{n}^{1}$ is the irrigation end time, $T$ is the total time of the water supply to the main canal, $t_{x_{j}}$ is the minimum time required for a branch canal to complete the irrigation task after $j$-th backtracking times, $I_{j}\left[i_{j}\right]$ is the set of the branch canals obtained for the $\mathrm{j}$-th backtracking times and $t_{I_{j}}$ is the amount of time required for the irrigation of each branch canal selected by the $j$-th backtracking times.

(2) Flow rate constraint

$$
Q-\left(\sum_{m=1}^{j} G_{m}-\sum_{n=1}^{j-1} G_{x_{n}}\right)>0
$$

where the symbols used in Equation (5) are described in Equation (1). 
(3) Water quantity constraint

$$
\begin{gathered}
\sum_{n=1}^{N} Q_{n}^{0}\left(t_{n}^{1}-t_{n}^{0}\right) \leq W \\
Q_{n}^{0}\left(t_{n}^{1}-t_{n}^{0}\right) \geq W_{n} \cdot A_{n}
\end{gathered}
$$

where $W$ is the maximum inflow of water, $W_{n}$ is the irrigation quota of water for crop areas, $A_{n}$ is the crop area and $Q_{n}^{0}$ is the net flow of water distribution for the branch canal " $n$ ".

The biggest difference between the BSA and other similar algorithms is that the BSA does not rely on the objective function for obtaining the uniquely determined optimal solution, while other common algorithms provide approximate solutions. The BSA is equivalent to the replacement combination problem. First, multiple diversion branches were arranged and combined, and then the objective function was used to screen different combinations to select the solution that best met the objective. When a branch canal had received sufficient irrigation water, it would exit the current combination. We needed to combine the branch canals that still needed water diversion and screen them again. This step was repeated until all branch canals had met the water distribution requirements. Therefore, the BSA was more suitable than other algorithms for the area where the number of channels was not so complicated in the process of finding a channel irrigation solution and the consideration of all the possible combinations was more efficient. To deal with the optimal water distribution problem in the canal system, the core concept of using the BSA was the progressive selection of the optimal permutation combination to ensure that the remaining flow would tend toward the minimum [18]. Considering the canal system of the irrigation area and the unique solution of the BSA, the optimization model for the Xiying irrigation area was selected. On the basis of the BSA, after optimization of the algorithm, the actual running problem of the results was analyzed and an unsteady flow simulation model of the canal system corresponding to the optimization scheme was also established. The feasibility of the scheme was verified by running the model and checking the consistency of the operation results (the change process of the water level and the discharge of the channel flow) in the actual situation.

\subsection{Unsteady Flow Simulation Model of Canal System}

\subsubsection{Model Structure and Construction}

MIKE 11 software has a good user interface; therefore, it was used to build the simulation model for the irrigation area. MIKE 11 software includes multiple application modules such as hydrodynamic simulation, water quality analysis, and flood forecasting. The hydrodynamic model section file, river network file, boundary file and parameter file were constructed to make the final calculation file.

On the basis of channel cross-sectional data, the point coordinate data of the river section were read and processed to set the basic unit in the calculation process, which was Cross Sections.xns11. Then, River Network.nwk11 connected and coupled the basic units of the canals. HD Parameters.hd11 was used to set the supplementary parameters required for the simulations. Default values were used for most parameters, and satisfactory simulation results were obtained. The Manning coefficient type was selected as 0.022 [25].

Boundary Condition.bnd 11 was used to define and constrain the interactions between the model and the external environment. The common types of boundaries were open and additional. The open boundary was a node with only one end connected to the model, which was necessary at either the beginning or the end of the river or channel to handle the water flow equation. The additional boundaries interacted with a portion of the river network and included point source boundaries, distributed boundaries, and global boundaries. A new boundary file meant that the constraints required for the import and export of the channel were set. In the simulation process, the selected boundary type was the open boundary (OPEN) and the water level or discharge definition was defined for the boundary. Other types could also be selected on the basis of the actual simulation needs of the model. In the canal simulation process, OPEN boundary was used to constrain the channel. For the 
OPEN boundary setting, the other modules of the MIKE 11 software were used to set the time series file, which corresponded to each channel according to the canal data and the simulation requirements. This setting further defined and explained the water level flow of the OPEN boundary. The types of constraints, which were used in the irrigation channel simulation of the irrigation district, included the conditions of the flow boundaries (Inflow), the water level boundaries (Water Level) and the flow and water level boundaries (Q-h). The downstream boundary of the channel adopted the outer boundary constraint. By considering the actual channel operation mode, the downstream normal water level operation constraint was set in the simulation process.

The four previously mentioned files were assembled into the calculation file, and the corresponding start time, step size and result output interval were set. If the conditions given by the water distribution scheme were feasible, the water flow information of the channel would be taken. Otherwise the model would give an unrealized high water level or excessive flow and may even terminate the calculation.

\subsubsection{Model Verification}

Yintang Irrigation District is located in Tangyuan County, Heilongiiang Province, China. The Tangwang River is the main source of irrigation water in this region. Its north trunk channels and the ninth and tenth branch channels were selected as the simulation region. A schematic diagram of the channel arrangement is shown in Figure 2. The mathematical model of the river network water supply in the above-mentioned areas was established using MIKE 11 software. The actual flow of water in each channel within $200 \mathrm{~min}$ was calculated through the generalization of the river network and the river section and the setting of internal and external boundaries. At the same time, the model calculation results were compared with the measured data of the channel, shown in Figure 3. The results showed that the model can reflect the motion characteristics of the river network in the region and verified the rationality of the model. It was applied to the verification calculation process of the water distribution scheme in the Xiying Irrigation District.

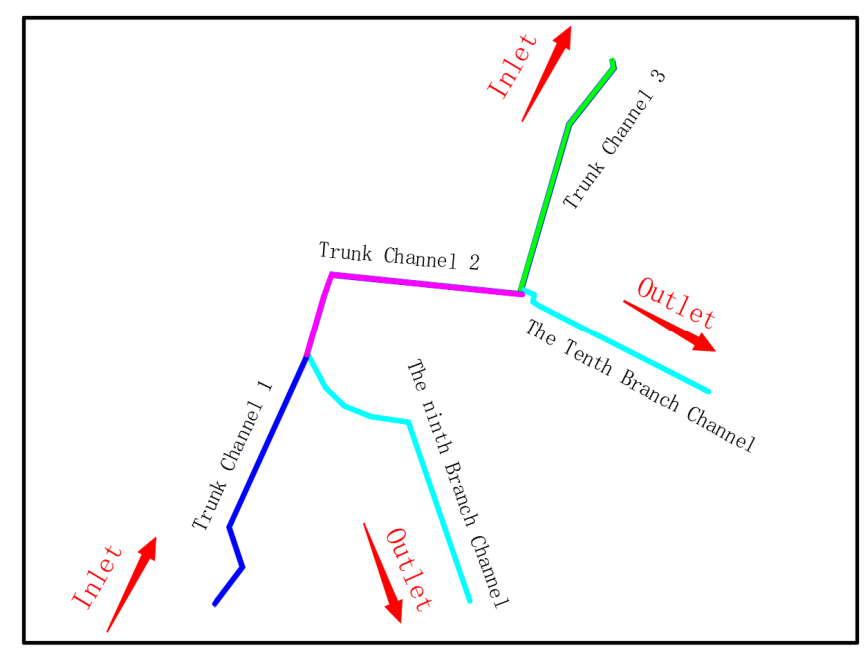

Figure 2. Layout of the channel. 


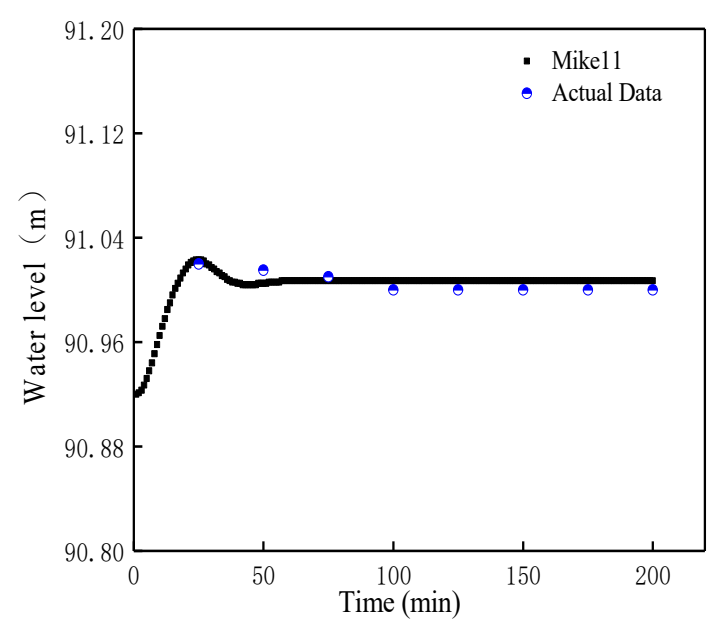

(a) The gate opening condition

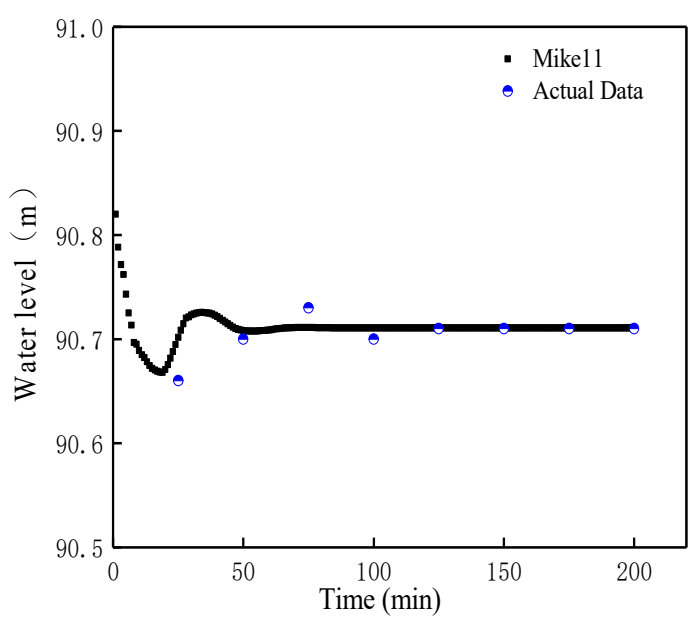

(b) The gate closing condition

Figure 3. Comparison of the measured water level line and the simulation calculation results: (a) the change of the water level in the upper section of Trunk Channel 1 and (b) the change of the water level in the upper section of Trunk Channel 2.

\section{Results and Discussion}

\subsection{Water Distribution Scheme Given by BSA}

According to the water distribution requirements of the Xiying Canalization in 2008, it was ensured that the irrigation time was controlled within 15 days. The irrigation water distribution time and flow rate (as shown in Figures 4 and 5, respectively) were obtained by the BSA model using the basic parameters as input. Under the constraint of meeting the 15 days upper limit of irrigation time, the BSA model selected the irrigation sequence of each branch canal, gave the corresponding irrigation start and end times and also reduced the irrigation cycle, as shown in Figure 4. Figure 5 shows the respective working flow of the five branch canals, which met the constraints of the no-rush and no-sediment operations of the channel. It was in line with the actual operation of the field. The bar chart of the amount of unused water obtained under single backtracking is shown in Figure 6. This meant that the amount of unused water was uneven, which was due to a higher number of available branch canals using the BSA model in the early stages. Therefore, it was easier to make the remaining flow reach zero in the unit time. The accumulation curve of unused water, shown in Figure 6, showed that there was a pause platform in the third retrospective, which was due to the fact that the time used for the ten times backtracking was extremely short. Even if the flow rate of the unused water was high, it was impossible to accumulate a large amount of unused water in a short time.

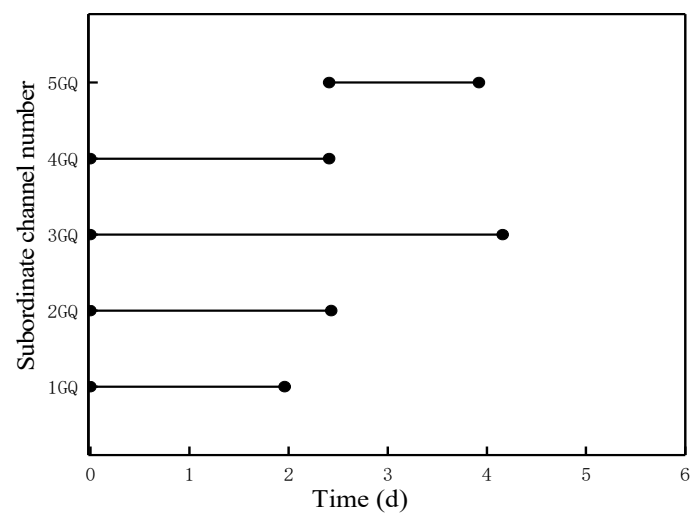

Figure 4. Distribution of water distribution time in the branch of Xiying Irrigation District. 


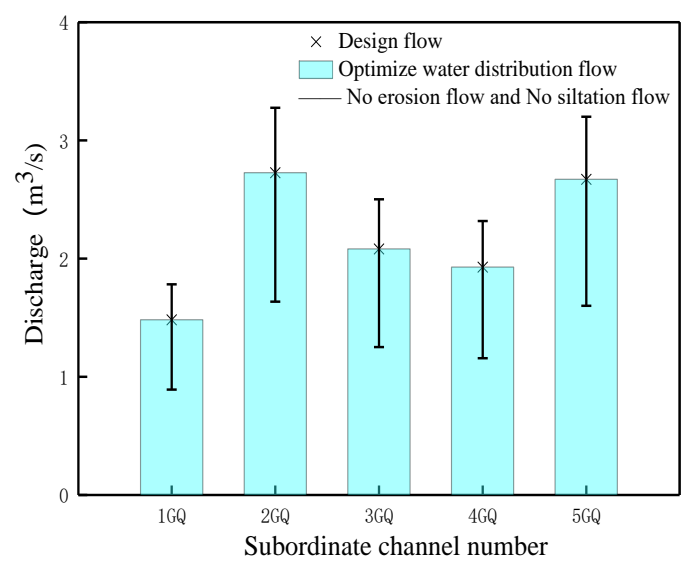

Figure 5. Distribution of secondary channel flow in Xiying Irrigation District.

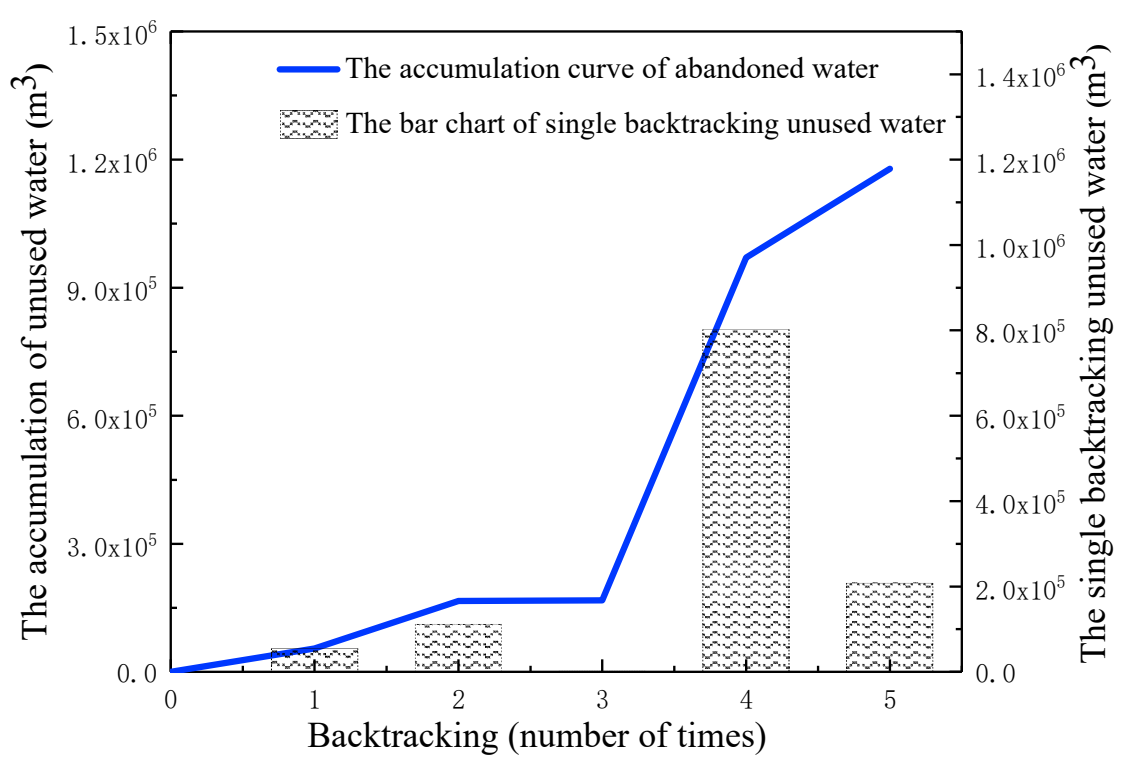

Figure 6. Remaining water curve of the backtracking-search algorithm (BSA).

The optimization results clearly showed that the BSA could complete the irrigation task in a short time by optimizing the water distribution of the canal system. It was conducive to the more efficient and economical use of water resources in irrigation districts. Increasing water resources beyond the limits of crop growth will not increase crop yields. Quantitative and efficient irrigation of irrigation areas enables the precise and cautious use of field water, rather than more fearless and optimistic water use. A balanced water supply must be maintained in order to sustain the agricultural water resources instead of more supply, and the traditional water supply programs must be reformed and optimized. With the efficient and economical use of irrigation water resources, irrigation water could also be used to reduce the pressure of urban water use or used as ecological water to better meet ecological needs. This takes into account the sustainability of water resources in other sectors and areas and reflects our commitment to promoting the sustainability of more water resources through the optimal management of agricultural water.

However, to propose a water distribution scheme for an actual irrigation district, optimal water use should be considered along with verification from practical aspects and simple economical use. For the verification of water use schemes in large-scale irrigation districts, it is not feasible to select field verification. With change in the irrigation area, performing an equal proportion of the experimental model for analysis cannot be adjusted in time and is also uneconomical. The effect of the BSA scheme in the scope of the Xiying main canals and its branch canals was evaluated from the simulation point 
of view through the numerical simulation of the channel water level and flow rate of the retrospective water distribution scheme.

\subsection{Unsteady Flow Information Based on Simulation}

The simulation area adopted relative elevation. The relative elevation in the simulation starting point of the total main channel was set to $100 \mathrm{~m}$, while other required elevations were calculated according to the longitudinal slope. The simulation duration of each channel was set to $200 \mathrm{~min}$, the time step was taken for $1 \mathrm{~s}$ and the downstream normal water depth operation mode was adopted. The upstream flow of Canal ZGQ (as shown in Figure 1) was set to a design flow of $8.41 \mathrm{~m}^{3} / \mathrm{s}$ by considering the efficiency of irrigation. The water flow dispatched from other branch channels was allocated according to the optimized water distribution scheme, i.e., the gate of each tributary was opened and closed according to the time shown in Figure 4, while the diversion flow of each branch canal was increased from 0 to the operating flow (as shown in the column in Figure 5) and remained stable. The calculations were performed according to the above conditions and the simulation results are shown in Figure 7.

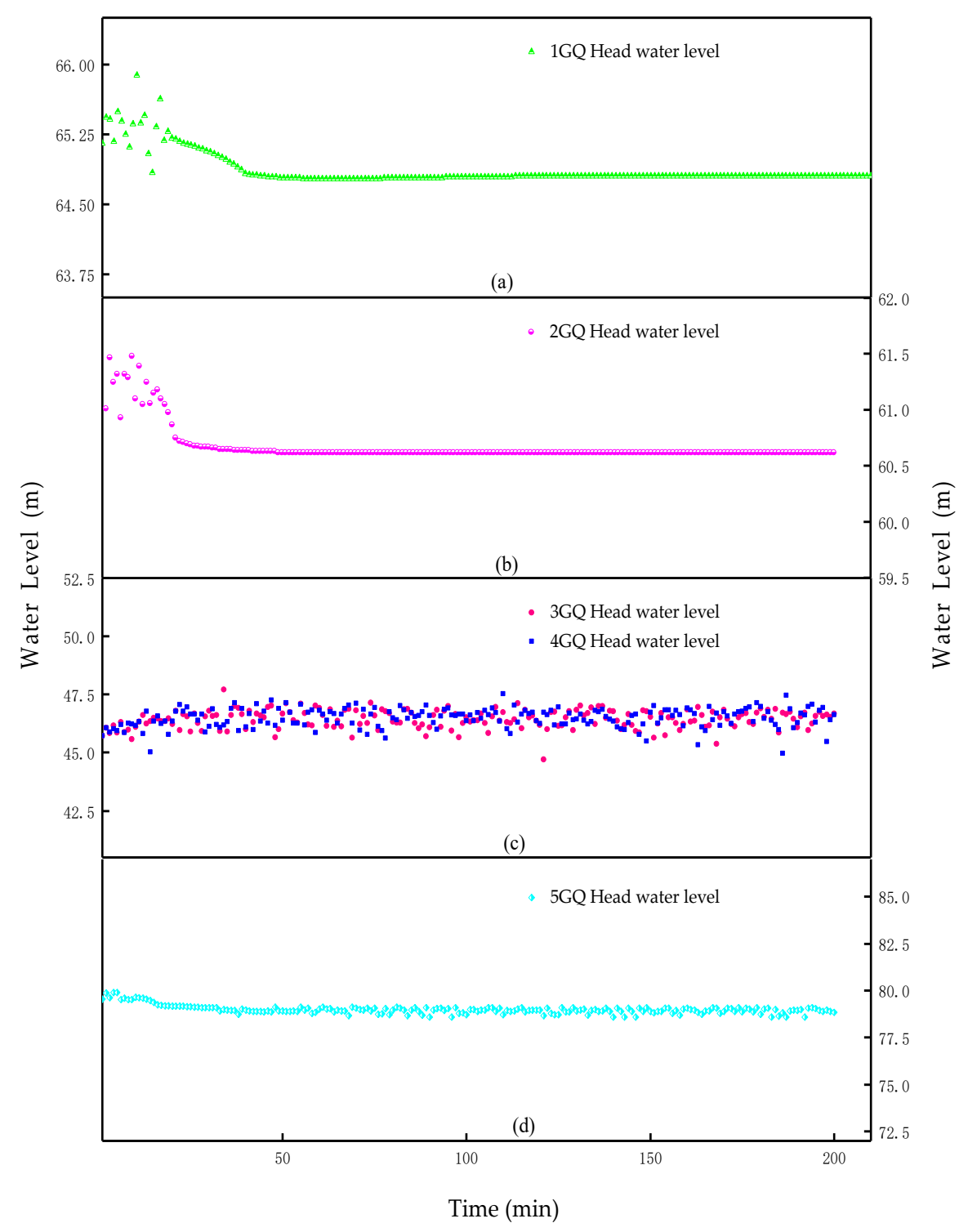

Figure 7. Process diagram of the change of the head water level in the branch canal. 
Figure 7 reflects the changes in the water level in the heads of the five branch canals. The head water levels of each canal had gradually transitioned to a stationary stage after certain fluctuations, as shown in Figure 7a,b,d. The canals "3GQ" and "4GQ" (as shown in Figure 1) were connected to the end of the main canal to form a Y-shaped channel; therefore, the water levels were different before the gate, which are shown in Figure 7c. The water level fluctuated continuously in 200 min simulation time and was difficult to stabilize. Canals 3GQ and 4GQ were located at the end of the primary canal; therefore, the water transfer operation process of the main canal and other secondary canals greatly affected their water level. There were constant fluctuations in the water level before the gate. Figure 8 shows that the flow discharges varied with time at the end of each secondary channel in the BSA model. The optimization results met the field requirements, and the water was supplied to the sub-regions. The change in the opening degree of each channel gate was calculated according to the calculation correlation of the gate opening degree and the simulated data (as shown in Figure 9). The scattered point, in Figure 9, represents the calculated value and shows that it was fitted into the actual running process of the gate (the solid line represents the fitted value), which was basically in line with the running requirements in the actual situation.

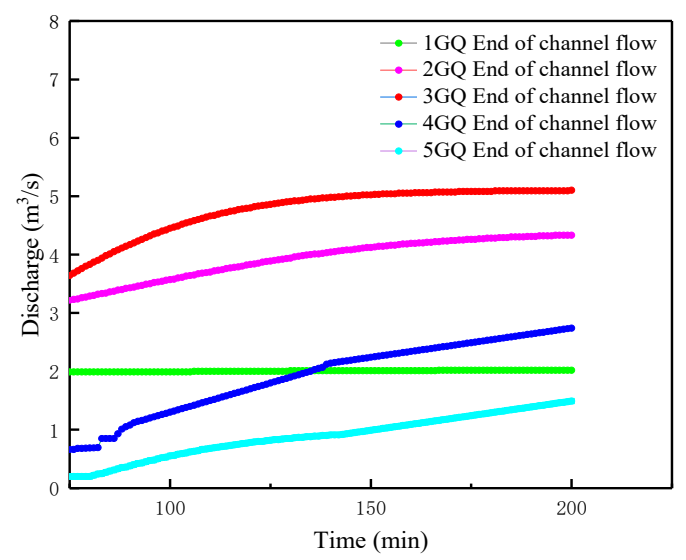

Figure 8. Process diagram of the discharge. Change at the end of secondary canals.

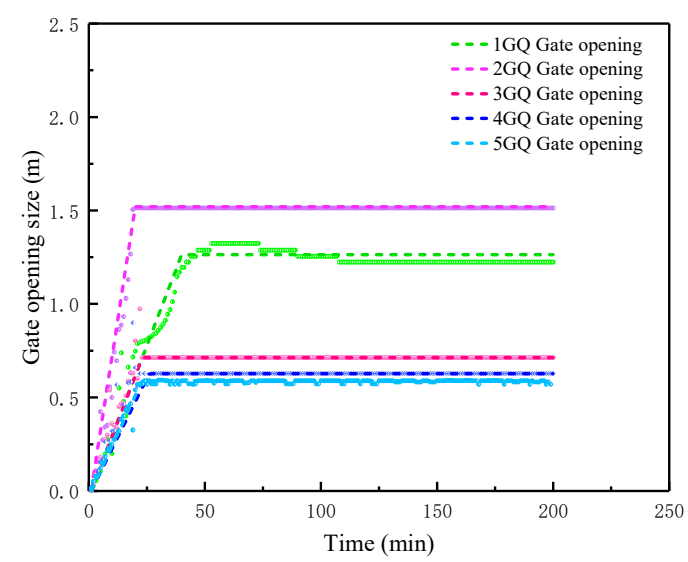

Figure 9. Process diagram of gate opening. Change at the secondary canals.

Hydrodynamic calculations are used to analyze the feasibility of the optimization results, which means that the given water distribution results are processed into boundary conditions in the MIKE calculation process so that the channel flow can be simulated under the constraints of the water distribution scheme. If the scheme is not reasonable, the boundary conditions will not be successfully coupled to the MIKE 11 and the model will not run. For the Xiying Irrigation District, it was feasible to 
process the optimization results as boundary conditions. This preliminarily shows that the scheme given by the BSA is feasible.

The hydrodynamic output results were processed and analyzed, and the information flow trends of each typical section conformed to the actual situation. Further analysis and processing of the water flow information gave the change process of the opening degree of each gate, and the calculated value can also fit well with the trend of a polyline that is convenient for actual operation. Through the successful simulation of the water distribution scheme and the analysis of simulation results, it was proved that the BSA scheme was feasible in the Xiying Irrigation District. For other irrigation areas, canals and irrigation systems, considering the safety and economic benefits, this method can still be used for feasibility assessment and analysis before using it in the field.

\section{Conclusions}

The channel hydrodynamic simulation and backtracking-search algorithm were combined in this study to verify the irrigation scheme of an irrigation district in an arid area, the Xiying Irrigation District, and showed that the hydrodynamic model was suitable for use when the BSA provided a water schedule. On the basis of a previous research study, a model was constructed to estimate the feasibility of optimized results. The hydrodynamic values of each channel flow were subsequently used to calculate the gate opening by using the sluice gate calculation correlation. Finally, the estimated results of that opening were adjusted and matched under the actual operational requirements. Several main conclusions were derived from this study, which are as follows:

(1) The BSA was applied to optimize the water dispatching in the Xiying Irrigation District. The water distribution discharging and the backflow cumulative residual water volume of each channel were obtained. The results shown in Figure 4 to Figure 6 show that the water distribution scheme met the optimization conditions of less time and less residual water. From the perspective of water efficiency, this scheme had preliminary feasibility.

(2) According to the hydrodynamic simulation, the water level and flow transition information for the whole canal system was obtained. By the application of MIKE 11 to some typical channels in Yintang Irrigation District, the model calculation results obtained matched the actual measured values of existing irrigation districts and indicated that the hydrodynamic model could be used to verify the water regime of the irrigation districts.

(3) After coupling the water distribution scheme optimization by the BSA with boundary conditions, the developed hydrodynamic calculations of the channel were used as a judgment criterion for the optimal allocation of irrigation water. The consistency in the hydrodynamic model calculations and the final output results showed that the water distribution scheme could be applied practically from the numerical simulation angle. A combination of the calculation correlation of the gate opening degree and the actual operating constraints determined the operation process of the gate.

The water distribution model is a theoretical innovation that also has a high practicability. The hydrodynamic value of unsteady flow provides a basis for the verification of a water distribution optimization scheme. By comparing the feasibilities of different irrigation water schedules from the hydrodynamics point of view, a preferable irrigation system can be chosen in order to overcome the problem of water shortage and realize the sustainable utilization of water.

Author Contributions: Conceptualization, J.W. and Y.H.; methodology, J.W. and Y.H.; software, J.W. and J.C.; validation, J.W.; formal analysis, J.W. and Y.H.; resources, J.W., J.C., T.L. and Y.H.; data curation, J.W. and T.L.; writing-original draft preparation, J.W.; writing—review and editing, J.W. and Y.H.; visualization, J.W. and J.C.; supervision, J.C. and Y.H.; project administration, Y.H. All authors have read and agreed to the published version of the manuscript.

Funding: The authors express gratitude for the financial support. This research was funded by the National Natural Science Foundation of China, Grant No. 51979275, by the National Key Research and Development Program of China under Grant Nos. 2017YFC0403203 and 2017YFD0701003, by the Jilin Province Key Research and Development Plan Project under Grant No. 20180201036SF, by the Open Fund of Synergistic Innovation Center of Jiangsu Modern Agricultural Equipment and Technology, Jiangsu University, under Grant No. 4091600015, by 
the Open Research Fund of the State Key Laboratory of Information Engineering in Surveying, Mapping and Remote Sensing, Wuhan University, under Grant No. 19R06, and by the Chinese Universities Scientific Fund under Grant No. 10710301.

Acknowledgments: The authors are very grateful for the funding support.

Conflicts of Interest: The authors declare no conflict of interest.

\section{References}

1. Amprako, J.L. The United Nations World Water Development Report 2015: Water for a Sustainable World; UNESCO: Paris, France, 2015.

2. Liu, J.; Mao, G.; Hoekstra, A.Y.; Wang, H.; Wang, J.; Zheng, C.; van Vliet, M.T.H.; Wu, M.; Ruddell, B.; Yan, J. Managing the energy-water-food nexus for sustainable development. Appl. Energy 2018, 210, 377-381. [CrossRef]

3. Li, M.; Fu, Q.; Singh, V.P.; Ji, Y.; Liu, D.; Zhang, C.; Li, T. An optimal modelling approach for managing agricultural water-energy-food nexus under uncertainty. Sci. Total Environ. 2019, 651, 1416-1434. [CrossRef] [PubMed]

4. Karabulut, A.A.; Crenna, E.; Sala, S.; Udias, A. A proposal for integration of the ecosystem-water-food-land-energy (EWFLE) nexus concept into life cycle assessment: A synthesis matrix system for food security. J. Clean. Prod. 2018, 172, 3874-3889. [CrossRef]

5. Ma, M.; Zhao, M. Research on an Improved Economic Value Estimation Model for Crop Irrigation Water in Arid Areas: From the Perspective of Water-Crop Sustainable Development. Sustainability 2019, 11, 1207. [CrossRef]

6. $\quad$ Elliott, J.; Deryng, D.; Müller, C.; Frieler, K.; Konzmann, M.; Gerten, D.; Glotter, M.; Flörke, M.; Wada, Y.; Best, N.; et al. Constraints and potentials of future irrigation water availability on agricultural production under climate change. Proc. Natl. Acad. Sci. USA 2014, 111, 3239-3244. [CrossRef]

7. Grogan, D.S.; Zhang, F.; Prusevich, A.; Lammers, R.B.; Wisser, D.; Glidden, S.; Li, C.; Frolking, S. Quantifying the link between crop production and mined groundwater irrigation in China. Sci. Total Environ. 2015, 511, 161-175. [CrossRef]

8. Hall, W.A.; Nathan, B. The dynamic programming approach to water-resources development. J. Geophys. Res. Atmos. 1961, 66, 517-520. [CrossRef]

9. Reca, J.; Roldán, J.; Alcaide, M.; López, R.; Camacho, E. Optimization model for water allocation in deficit irrigation system I. Description of the model. Agric. Water Manag. 2001, 48, 103-116. [CrossRef]

10. Wardlaw, R.; Bhaktikul, K. Application of a genetic algorithm for water allocation in an irrigation system. Irrig. Drain. 2001, 50, 159-170. [CrossRef]

11. Zhang, S.B.; Qie, Z.H.; Wu, X.M.; Zhang, Z.Y.; Tian, X.J. Irrigation system optimization under non-sufficient irrigation based on elitist non-dominated Sorting genetic algorithm. In Proceedings of the 2008 Chinese Control and Decision Conference, Yantai, China, 2-4 July 2008. [CrossRef]

12. Chen, Z.; Song, N.; Wang, J.; Sun, J.; Liu, Z.; Liu, X. A decision support system for water-saving irrigation management. Intell. Autom. Soft Comput. 2010, 16, 923-934. [CrossRef]

13. Wang, Y.B.; Wu, P.T.; Zhao, X.N.; Jin, J.M. Water-saving crop planning using multiple objective chaos particle swarm optimization for sustainable agricultural and soil resources development. Clean Soil Air Water 2012, 40, 1376-1384. [CrossRef]

14. Karasekreter, N.; Bascifci, F.; Fidan, U. A new suggestion for an irrigation schedule with an artificial neural network. J. Exp. Theor. Artif. Intell. 2013, 25, 93-104. [CrossRef]

15. Akbari, M.; Gheysari, M.; Mostafazadeh-Fard, B.; Shayannejad, M. Surface irrigation simulation-optimization model based on meta-heuristic algorithms. Agric. Water Manag. 2018, 201, 46-57. [CrossRef]

16. Jin, L.; Huang, G.H.; Fan, Y.R.; Nie, X.H.; Cheng, G.H. A hybrid dynamic dual interval programming for irrigation water allocation under uncertainty. Water Resour. Manag. 2012, 26, 1183-1200. [CrossRef]

17. Krishna, K.L.; UmaMahesh, N.V.; Prasad, A.S. Optimal multipurpose reservoir operation planning using Genetic Algorithm and Non Linear Programming (GA-NLP) hybrid approach. ISH J. Hydraul. Eng. 2018, 24, 258-265. [CrossRef] 
18. Sun, Z.P.; Chen, J.; Han, Y.; Huang, R.; Zhang, Q.; Guo, S.S. An optimized water distribution model of irrigation district based on the Genetic Backtracking Search Algorithm. IEEE Access 2019, 7, 45692-45704. [CrossRef]

19. Civicioglu, P. Backtracking Search Optimization Algorithm for numerical optimization problems. Appl. Math. Comput. 2013, 219, 8121-8144. [CrossRef]

20. Madasu, S.D.; Kumar, M.L.S.S.; Singh, A.K. Comparable investigation of backtracking search algorithm in automatic generation control for two area reheat interconnected thermal power system. Appl. Soft Comput. 2017, 55, 197-210. [CrossRef]

21. Islam, N.N.; Hannan, M.A.; Shareef, H.; Mohamed, A. An application of backtracking search algorithm in designing power system stabilizers for large multi-machine system. Neurocomputing 2017, 237, 175-184. [CrossRef]

22. Qi, X.B.; Huang, Z.D.; Qiao, D.M.; Zhang, X.C.; Li, P.; Andersen, M.N. Advances in rational allocation of water resources in irrigation districts. Adv. Water Sci. 2015, 26, 287-295. (In Chinese) [CrossRef]

23. Fang, T.Y.; Gu, Y.; He, X.L.; Liu, X.D.; Han, Y.; Chen, J. Numerical Simulation of Gate Control for Unsteady Irrigation Flow to Improve Water Use Efficiency in Farming. Water 2018, 10, 1196. [CrossRef]

24. Yevjevich, V.M. Bibliography and Discussion of Flood-Routing Methods and Unsteady Flow in Channels; US Government Printing Office: Washington, DC, USA, 1964.

25. Panton, R.L. Incompressible Flow. Phys. Today 1985, 52, 500-501. [CrossRef]

(C) 2020 by the authors. Licensee MDPI, Basel, Switzerland. This article is an open access article distributed under the terms and conditions of the Creative Commons Attribution (CC BY) license (http://creativecommons.org/licenses/by/4.0/). 